\title{
Characterization and Ex vivo Studies of Nanoparticle Incorporated Transdermal Patch of Itraconazole
}

\author{
M. T. RAO*, Y. S. RAO, VIJAYA RATNA J1 AND KAMALA KUMARI PV \\ Vignan Institute of Pharmaceutical Technology, Duvvada, Visakhapatnam-530049, ${ }^{1} \mathrm{AU}$ College of Pharmaceutical Sciences, \\ Andhra University, Visakhapatnam-530003, India
}

Rao et al.: Characterization and Ex Vivo studies of Itraconazole

\begin{abstract}
Itraconazole, an antifungal drug possess poor solubility, gastrointestinal irritation and first pass effect. Hence in the present work it was initially made as nanoparticles to facilitate absorption and at later stage nanoparticles loaded transdermal patches were developed using promising nanoparticles. Nanoparticles were prepared with Eudragit RL 100 by solvent displacement technique. Formulations F1 to F9 were prepared by using different concentrations of Eudragit RL 100 and polyvinyl alcohol and evaluated for drug content, drug release, entrapment efficiency and mean particle size. The selected formulation was lyophilized to incorporate these formed nanoparticles into transdermal patch by varying concentrations of hydroxy propyl methyl cellulose K100M, polyvinyl alcohol and polyethylene glycol 400 . The obtained patches were evaluated for thickness, tensile strength, folding endurance, moisture absorption and moisture content and the drug release showed biphasic release. All the formulations followed first order kinetics, diffusion controlled and fickian release. Flux (ex vivo) studies on rat skin of optimized formulation have high flux of $63.24 \mu \mathrm{g} / \mathrm{cm}^{2} / \mathrm{h}$ compared with pure drug, prepared itraconazole ointment $39.15 \mu \mathrm{g} / \mathrm{cm}^{2} / \mathrm{h}$ and prepared itraconazole gel $40.01 \mu \mathrm{g} / \mathrm{cm}^{2} / \mathrm{h}$. The permeability of itraconazole nanoparticle loaded transdermal patch showed 2.63 folds enhancement compared to pure drug. Scanning electron microscopes clearly showed the drug loaded nanoparticle embedment in polymeric transdermal patch. Formulated nanoparticle loaded itraconazole transdermal patch can be successfully used as a carrier for enhancing transdermal permeation and the bioavailability.
\end{abstract}

Key words: Itraconazole, nanoparticle, transdermal patch, biphasic releasese

Transdermal drug delivery (TDD) offers many benefits, but it has proven difficult to discover drugs small and lipophilic enough to permeate effectively through the skin barrier ${ }^{[1]}$. Transdermally delivered drugs often have better patient compliance than more painful/invasive alternative routes that require needle injection $^{[2]}$. Transdermal routes also offer the benefit of bypassing the first-pass metabolism in the liver that orally delivered drugs undergo. Drug formulations and concentrations can also be tuned to allow controlled release of drug into the body over long periods of time; thereby, decreasing the need for multiple doses/applications ${ }^{[3]}$. For these reasons, Transdermal drug delivery system (TDDS) are an active area of research; however, few Food and Drug Administration (FDA) approved transdermal drug formulations currently exist ${ }^{[4,5]}$. Currently, the research goal is to use technology to enhance TDDS, and to discover novel methods to allow skin permeation of larger,

*Address for correspondence

E-mail: thrinadh_81@rediffmail.com

September-October 2020 hydrophilic drugs once thought to be impermeable to the skin. TDDS can be an effective path for the systemic availability of drugs. Transdermal patches are novel drug delivery systems for the skin application to attain a systemic effect. Application of the TDDS system offers many clinical benefits over other routes. It provides a consistent drug release, maintain a steady blood level profile which can reduce systemic side effects, convenient, user complaint, which contribute to improve patient acceptance ${ }^{[6]}$. Steady absorption of a drug for a prolonged period eliminates the required for frequent dosing of the drugs which contribute to improved patient compliance ${ }^{[7]}$. Many strategies have

This is an open access article distributed under the terms of the Creative Commons Attribution-NonCommercial-ShareAlike 3.0 License, which allows others to remix, tweak, and build upon the work non-commercially, as long as the author is credited and the new creations are licensed under the identical terms

Accepted 21 December 2020

Revised 21 September 2020

Received 21 April 2020

Indian J Pharm Sci 2020;82(5):809-818 
been employed to better the transdermal delivery and dermal of drugs, e.g., improving the partitioning between the formulation, increasing the efficient concentration of the drug in the vehicle, the use of chemical penetration enhancers and different physical enhancement methods ${ }^{[8,9]}$. Furthermore, carrier systems like liposomes, nanoparticles or micro particles have explored ${ }^{[10-12]}$.

TDDS formulations were preferable over the tablet (conventional) or capsule preparations as it has several advantages like it controlled release pattern thus minimizing the dosing frequency ${ }^{[13,14]}$. The main aim of this study was to investigate the influence of nanoparticle loaded transdermal delivery for improved penetration and permeation, patient compliance and prolonged action.

\section{MTERIALS AND METHODS}

\section{Materials:}

Itraconazole was received as a gift sample from Ranbaxy laboratories Ltd., Dewas (India). Eudragit RL100 (Rohm Pharma, Germany), Liquid paraffin, white soft paraffin, methanol, hydroxyl propyl methyl cellulose (HPMC), polyethylene glycol400 (Sigma Aldrich, USA), All other chemicals were analytical grades.

\section{Preparation of nanoparticles:}

Polymeric nanoparticles of itraconazole were prepared with Eudragit RL100 by solvent displacement technique. The polymer (100 mg) along with itraconazole $(100 \mathrm{mg})$ was dissolved in $20 \mathrm{ml}$ acetone and methanol (3:1), which formed the organic phase. This organic phase was poured through an orifice of size $0.22 \mu \mathrm{m}$, at the rate of $1 \mathrm{ml} / \mathrm{min}$ under atmospheric pressure into an aqueous medium $(40 \mathrm{ml})$ containing $1 \%$ polyvinyl alcohol (PVA) (hydrophilic surfactant) as a stabilizer under moderate magnetic stirring $(1000 \mathrm{rpm})$. After the addition of the organic phase, stirring was continued for $1 \mathrm{~h}$ at the same speed. After $1 \mathrm{~h}$, it was sonicated for 2 min to obtain desired particle size. Later the colloidal dispersion was subjected to heating under reduced pressure at $580^{\circ}$ to remove acetone \& methanol (solvents) and the solution concentrated depends on the solvent: non-solvent ratio ${ }^{[15]}$. Different batches of different formulation were prepared as given in Table 1.

\section{Evaluation of nanoparticles:}

\section{Particle size and poly dispersibility index ${ }^{[16]}$}

Particle size, poly dispersibility index of ethosomes was measured by Photon Correlation Spectroscopy (PCS) Delsa Nano C (Beckman Coulter Counter, USA) particle size analyzer. Samples were diluted appropriately with the aqueous phase of the formulation for the measurements. The samples were kept in polystyrene cuvettes, and observations were made at a $165^{\circ}$ fixed angle every time.

\section{Drug content}

Nanoparticles with drug equivalent to $50 \mathrm{mg}$ were dispersed in $100 \mathrm{ml}$ of Phosphate Buffered Saline (PBS) 7.4 buffer and stirred for $2 \mathrm{~h}$. Samples were diluted suitably and analyzed in UV spectrophotometer at $265 \mathrm{~nm}$.

\section{Entrapment efficiency}

The concentration of the free drug in the aqueous phase of nanoparticles loaded with itraconazole was measured $^{[17,18]}$. The suspension of nanoparticles prepared was centrifuged in High Speed Cooling Centrifuge at $10000 \mathrm{rpm}$ for $45 \mathrm{~min}$. The supernatant was collected and analyzed using UV-Visible spectrophotometer at $265 \mathrm{~nm}$ after suitable dilutions. The drug entrapment efficiency (EE) was calculated using the following equation:

Percentage entrapment efficiency $=\mathrm{D}_{\mathrm{T}}-\mathrm{D}_{\mathrm{UE}} / \mathrm{D}_{\mathrm{T}} \times 100$ Where, DT is the total amount of drug, DUE is the amount of drug unentrapped

\section{In vitro diffusion studies ${ }^{[19]}$}

In vitro drug release of itraconazole from the nanoparticles was performed by diffusion technique using Franz-diffusion cell. The dialysis membrane

TABLE 1: FORMULATIONS OF ITRACONAZOLE NANOPARTICLES

\begin{tabular}{lccccccccc}
\hline Ingredients & F1 & F2 & F3 & F4 & F5 & F6 & F7 & F8 & F9 \\
\hline Drug(mg) & 100 & 100 & 100 & 100 & 100 & 100 & 100 & 100 & 100 \\
Eudragit RL 100 $(\mathrm{mg})$ & 100 & 100 & 100 & 200 & 200 & 200 & 300 & 300 & 300 \\
Acetone:Methanol $(\mathrm{mL})$ & $1: 3$ & $1: 3$ & $1: 3$ & $1: 3$ & $1: 3$ & $1: 3$ & $1: 3$ & $1: 3$ & $1: 3$ \\
PVA $(\%)$ & 1 & 2 & 3 & 1 & 2 & 3 & 1 & 2 & 3 \\
Water $(\mathrm{mL})$ upto & 40 & 40 & 40 & 40 & 40 & 40 & 40 & 40 & 40 \\
\hline
\end{tabular}


(Himedia, thickness $0.025 \mathrm{~mm}$ ) was cut into equal pieces $(6 \mathrm{~cm} \times 2.5 \mathrm{~cm})$ and soaked into distilled water for $12 \mathrm{~h}$ before use. The drug release studies of the itraconazole solution is carried out in $10 \mathrm{ml}$ of phosphate buffer $\mathrm{pH} 7.4$ saline maintained at $37 \pm 2^{\circ}$ with a magnetic stirrer with constant heating equipment (IKA Auto Temp Regulator, Germany). A sample of $2 \mathrm{ml}$ of nanoparticles suspension was placed in receptor compartment. Aliquot samples of $1 \mathrm{ml}$ were withdrawn at the regular interval and replaced with same volume of fresh buffer. The aliquots were diluted with fresh media, if necessary. Amount of drug diffused through the membrane was measured by using U.V. spectrophotometer at the wavelength $265 \mathrm{~nm}$ against phosphate buffer (pH 7.4 saline) as the blank.

Selected formulation F5 was lyophilized to dry powder product by using Remi lyophilizer. The obtained lyophilized itraconazole nanoparticles equivalent to $100 \mathrm{mg}$ of drug were taken for incorporating it into transdermal patch as mentioned in Table 2.

\section{Preparation of the polymeric nanoparticles loaded itraconazole transdermal patch}

Transdermal patches were prepared by dissolving various concentrations of HPMC and Polyvinylpyrrolidone (PVP) in boiled water. A homogenous solution was made by using magnetic stirrer and a magnetic bead. The dried itraconazole nanoparticles of required amount were added to above solution and stirred for 20 min until a homogenous suspension was obtained. Then Polyethylene glycol (PEG) (0.5, 1 and $2 \%)$ as plasticizers were added ${ }^{[20,12]}$. The concentration of plasticizer used ranged from 1 to $5 \%$. The drug concentration in all films was $1 \%$. The solvent casting technique was used for preparation of the patches ${ }^{[21]}$. The solution mixture was poured on a specifically designed stainless steel spherical assembly consisting of two stainless steel plates of $7.9 \mathrm{~cm}$ internal diameter (area $48.99 \mathrm{~cm}^{2}$ ). The solvent was allowed to evaporate at $37 \pm 0.5^{\circ}$ and relative humidity $40 \pm 5 \%$. An inverted funnel was placed over the metallic assembly to prevent rapid evaporation of the solvent. All patches (Table 3) were separated from the casting assembly with the help of a sharp blade and then stored in the desiccator till further use.

\section{Evaluation of prepared itraconazole nanoparticles loaded transdermal patch:}

\section{Determination of the thickness}

The thickness of prepared films was measured using a micrometer (Mitutoyo, Kanagawa, Japan). Each film was measured for its thickness at 5 different points and the mean values were calculated ${ }^{[22]}$.

\section{Tensile Strength}

The tensile strength of the patch was evaluated by using the tensiometer ${ }^{[23]}$ (Erection and instrumentation, Ahmedabad). It consists of two load cell grips. The lower one was fixed and upper one was movable. Film strips with dimensions of $2 \times 2 \mathrm{~cm}^{2}$ were fixed between these cell grips, and force was gradually applied till the film broke. The tensile strength was taken directly from the dial reading in $\mathrm{kg}$.

\section{TABLE 2: EVALUATION PARAMETERS FOR PREPARED NANOPARTICLES}

\begin{tabular}{lccccc}
\hline F.Code & $\begin{array}{c}\text { Average particle } \\
\text { size }(\mathrm{nm})\end{array}$ & PDI & $\begin{array}{c}\text { Zeta potential } \\
(\mathrm{mVs})\end{array}$ & $\begin{array}{c}\text { Drug entrapment } \\
\text { efficiency }(\%)\end{array}$ & $\begin{array}{c}\text { Drug content } \\
(\%)\end{array}$ \\
\hline F1 & $354.7 \pm 0.61$ & $0.799 \pm 0.08$ & $20.1 \pm 1.34$ & $68.76 \pm 5.16$ & $93.745 \pm 0.62$ \\
F2 & $481.1 \pm 0.46$ & $0.385 \pm 0.05$ & $17.8 \pm 2.21$ & $76.25 \pm 0.93$ & $98.228 \pm 0.55$ \\
F3 & $584.1 \pm 0.05$ & $0.778 \pm 0.03$ & $15.2 \pm 1.43$ & $67.27 \pm 7.12$ & $96.063 \pm 0.34$ \\
F4 & $202.2 \pm 0.74$ & $0.641 \pm 0.02$ & $16.4 \pm 2.32$ & $62.13 \pm 1.88$ & $90.934 \pm 1.64$ \\
F5 & $194.2 \pm 0.42$ & $0.227 \pm 0.08$ & $18.6 \pm 2.31$ & $84.07 \pm 3.97$ & $97.628 \pm 0.78$ \\
F6 & $481.1 \pm 0.32$ & $0.385 \pm 0.03$ & $14.3 \pm 2.25$ & $72.18 \pm 3.20$ & $89.562 \pm 1.01$ \\
F7 & $333.6 \pm 0.87$ & $0.501 \pm 0.03$ & $17.0 \pm 2.51$ & $78.13 \pm 2.86$ & $99.664 \pm 0.33$ \\
F8 & $294.8 \pm 0.53$ & $0.594 \pm 0.02$ & $14.4 \pm 1.42$ & $70.65 \pm 4.49$ & $95.521 \pm 0.65$ \\
F9 & $302.9 \pm 0.43$ & $0.807 \pm 0.05$ & $15.6 \pm 2.22$ & $67.77 \pm 4.44$ & $84.422 \pm 0.77$ \\
\hline
\end{tabular}

TABLE 3: COMPOSITION FOR ITRACONAZOLE NANOPARTICLES LOADED TRANSDERMAL PATCH

\begin{tabular}{lcccccc}
\hline \multicolumn{1}{c}{ Ingredients } & FTP1 & FTP2 & FTP3 & FTP4 & FTP5 & FTP6 \\
\hline Itraconazole nanoparticles (equivalent to) $\mathrm{mg}$ & 100 & 100 & 100 & 100 & 100 & 100 \\
HPMC K100M (mg) & 50 & 100 & 200 & 50 & 100 & 200 \\
PVP & 50 & 100 & 200 & 100 & 200 & 400 \\
PEG 400 (\%) & 0.5 & 1 & 2 & 0.5 & 1 & 2 \\
Methanol:Water (2:1) (ml) & 10 & 10 & 10 & 10 & 10 & 10 \\
\hline
\end{tabular}




\section{Folding endurance measurement}

This test was carried out to check the brittleness of the prepared films. It was done by repeated folding of the films in the same place until complete breakdown ${ }^{[24]}$. The number of folds required to break the films was determined.

\section{Moisture uptake study}

The films were put in a desiccators with silica gel for $24 \mathrm{~h}$ and weighed $\left(\mathrm{W}_{\mathrm{i}}\right)$ using Schimatzu digital balance. The films were then transferred to another desiccator containing saturated sodium chloride solution (relative humidity $75 \%$ ) at $25^{\circ}$ until a constant weight was obtained $^{[25]}$. After equilibrium was attained, the patches were taken out and weighed $\left(\mathrm{W}_{\mathrm{f}}\right)$. Moisture uptake capacity was calculated according to the following equation: Moisture uptake capacity $=\mathrm{W}_{\mathrm{f}}-\mathrm{W}_{\mathrm{i}} / \mathrm{W}_{\mathrm{i}} \times 100$, Where $\mathrm{W}_{\mathrm{f}}$ is the weight after attaining equilibrium, $\mathrm{W}_{\mathrm{i}}$ is the initial weight.

\section{Moisture content study}

The prepared patches were weighed $\left(\mathrm{W}_{\mathrm{i}}\right)$ and kept in a desiccator containing silica gel at $25^{\circ}$ until it showed a constant weight $\left(\mathrm{W}_{\mathrm{d}}\right)^{[18]}$. The moisture content was calculated according to the following equation:

Moisture content $(\%)=\mathrm{W}_{\mathrm{s}}-\mathrm{W}_{\mathrm{d}} / \mathrm{W}_{\mathrm{s}} \times 100$, Where $\mathrm{W}_{\mathrm{d}}$ is the weight of the dried polymer film $\mathrm{W}_{\mathrm{s}}$ is the weight after swelling

\section{In vitro release studies using USP dissolution tester}

The USP XXIII apparatus was used to determine the dissolution of the patches using paddle over the disc dissolution test unit, $900 \mathrm{ml}$ of PBS pH 7.4 was used as dissolution medium. The temperature was adjusted at $32 \pm 0.5^{\circ}$ and the speed at $50 \mathrm{rpm}$. Patches were cut into small strips each $2.5 \mathrm{~cm} \times 2.5 \mathrm{~cm}$ which were used for determination of the in vitro release of drug contained. Aliquots of $5 \mathrm{ml}$ were withdrawn through sintered glass filter at each time interval and replaced by equivalent amounts of fresh dissolution media. Blank experiments were simultaneously performed ${ }^{[26]}$. The cumulative amount of drug released after $12 \mathrm{~h}$ was determined by spectrophotometer at $265 \mathrm{~nm}$.

\section{Inherent permeability of pure drug across artificial and biological membrane:}

\section{Cellophane membrane}

Activation of cellophane was carried out by soaking the membrane for $10-12 \mathrm{~h}$ in buffer solution prior to use $\mathrm{e}^{[27]}$.

\section{Preparation of Rat Skin}

Albino Wistar 5-6 w old weighing 60-80 g were sacrificed by chloroform inhalation. The hair of test animals were carefully trimmed short $(<2 \mathrm{~mm})$ with a pair of scissors and the abdominal skin was separated from the underlying connective tissue using scalpel. The excised skin was placed on aluminium foil and the dermal side of the skin was gently teased off any adhering fat and or subcutaneous tissue. The skin was then carefully checked through a magnifying glass to ensure that samples were free from any surface regularity such as tiny holes or cervices in the portion that was used for transdermal permeation studies ${ }^{[28]}$.

\section{Permeation through cellophane membrane ${ }^{[3,29]}$}

Activated cellophane membrane was mounted to the donor compartment of the diffusion cell having a surface area of $5.065 \mathrm{~cm}^{2}$ and clamped with receptorcompartment which was filled with PBS pH 7.4. The diffusion cell was placed on the magnetic stirrer and the temperature maintained at $37^{\circ}$. One $\mathrm{mg} / \mathrm{ml}$ of itraconazole solution continuously stirred at $37^{\circ}$, removed at an appropriate interval for spectrophotometric determination and cell was immediately refilled with fresh receptor solution.

\section{Permeation through rat abdominal skin}

The rat skin free from ammonia were mounted to the donor compartment of the modified Franz diffusion cell having a surface area of $2.68 \mathrm{~cm}^{2}$ and clamped with the receptor compartment which was filled with PBS $\mathrm{pH}$ 7.4. The diffusion cell was then placed on magnetic stirrer and the temperature maintained at $37^{\circ}$. One $\mathrm{mg} / \mathrm{ml}$ of itraconazole solution was added to the donor compartment. The content of the receptor cell was continuously stirred at $37^{\circ}$, removed at appropriate intervals for High-performance liquid chromatography (HPLC) determination and cell was immediately refilled with fresh receptor for HPLC determination and cell was immediately refilled with fresh receptor solution.

\section{In vitro release studies ${ }^{[7,30,31]}$}

The in vitro permeation of itraconazole from optimized formulation was studied using locally fabricated diffusion cell. The effective permeation area of the diffusion cell and receptor cell volume was $2.2-2.5 \mathrm{~cm}^{2}$ and $25 \mathrm{ml}$ respectively. The temperature was maintained at $35 \pm 1^{\circ}$. The receptor constantly stirred by magnetic stirrer at $100 \mathrm{rpm}$. Albino abdomen rat skin (4 to $5 \mathrm{w}$ ) was mounted between the donor and the receptor 
compartments. The transdermal patch of itraconazole formulation was applied to the surface of the rat skin. Samples were withdrawn through the sample port of the diffusion cell at predetermined time intervals over $24 \mathrm{~h}$ and analyzed using spectrophotometer. The receptor phase was immediately replenished with equal volume of fresh diffusion buffer. Triplicate experiments were conducted for each study. In vitro skin permeation studies were conducted for different formulations and effect of variation in composition on permeation rate were studied.

\section{Calculation of flux ${ }^{[31,32]}$}

In vitro percutaneous flux $\left(\mu \mathrm{g} / \mathrm{cm}^{2} \times \mathrm{h}-1\right)$ of itraconazole from different formulations was calculated by plotting time versus the cumulative amount of active compound permeated through the skin and dividing the slope of the linear portion of the curve (steady-state) by the area of the skin surface through which diffusion took place.

Permeability coefficient $(\mathrm{P})$ is the velocity of drug passage through the membrane in $\mathrm{cm} / \mathrm{h}$. P was calculated from the slope graph of amount of drug permeated $(\mu \mathrm{g} / \mathrm{ml})$ vs. time. $\mathrm{P}=$ Slope $\times$ total amount of drug/ surface area of tissue, Flux is defined as amount of material flowing through a unit cross sectional barrier in unit time ${ }^{[33,34]}$. Flux $(J)=P \times C D$ Where, $C D$ is the concentration of drug in donor compartment.

The steady state permeation flux was determined from the slope of the linear portion of the cumulative amount of permeated $(\mathrm{Q})$ versus time $(\mathrm{t})$ plot. The lag time $\left(\mathrm{t}_{\mathrm{L}}\right)$ was determined by extrapolating the linear portion of $Q$ vs. $t$ curve to the abscissa. The permeability coefficient (P) was calculated using the relation derived from Fick's I law of diffusion, which is $\mathrm{P}=\mathrm{J} / \mathrm{C}$

\section{Scanning electron microscopy (SEM)}

Morphology of the prepared optimized itraconazole nanoparticles loaded transdermal patch was observed under scanning electron microscope. The sample was attached to the slab surface with double sided adhesive tape and the scanning electron photomicrographs were taken at different magnifications.

\section{RESULTS AND DISCUSSION}

Itraconazole nanoparticles were prepared by Nano precipitation or solvent displacement method. Several technical difficulties had to be overcome before succeeding in corporation of the drug into a Nano suspension. The selection of an organic phase that would be capable of solubilizing both the drug and the polymer was also a big challenge. For Nano suspension preparation, acetone (a water-miscible and low boiling point solvent) is the solvent of choice. However, the preparation of itraconazole loaded Nano suspension in acetone yielded an amorphous precipitate. Use of cosolvents was chosen as a solution to solve this problem of non-associated drug. Therefore, a co-solvent was utilized to optimize the solubility of both the drug and the polymer. This Nano suspension preparation process appears simple but involves complex interfacial hydrodynamic phenomena. The origin of the mechanism of nanoparticles formation may be explained in terms of interfacial turbulence or spontaneous agitation of the interface between two unequilibrated liquid phases, involving flow and is governed by the wellknown Marangoni effect, with movement in interfacial tension $^{[35]}$. It is possible to prepare a Nano suspension in the absence of any surfactant; but PVA, a highly aqueous soluble surfactant, is needed for physical stability of nano suspensions and also for maintaining the desired viscosity.

The particle size and particle size distribution are crucial parameters for the safe and effective permeation of the drug. The particle size, size distribution and entrapment efficiency of prepared formulations, from F1 to F9, are shown in Table 3 and in fig. 1. All the formulations showed a small mean size which is acceptable for transdermal delivery. The particle size and poly dispersibility index values are in the range of 194 to $584 \mathrm{~nm}$ and 0.227 to 0.807 respectively. The poly dispersibility index is probably a result which depends on a complex interplay of several phenomena involving the drug, the polymer, the solvents and the stirring rate. A poly dispersibility index value in the range of 0-0.05 indicates that the dispersion is mono disperse, if it is less than 0.7 , the dispersion is nearly mono disperse and if it is more than 0.7 , the dispersion is highly polydispersed ${ }^{[32]}$.

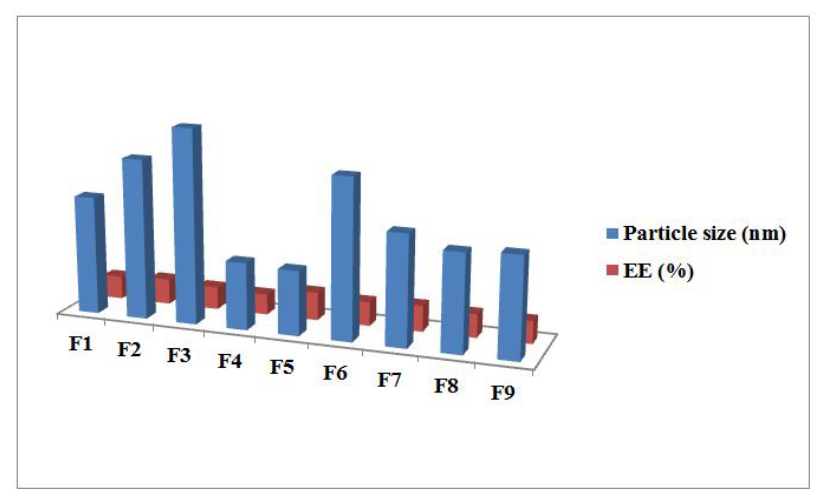

Fig. 1: Graph showing the particle size and entrapment efficiency of prepared itraconazole nanoparticles 
Values of drug content, in all the prepared formulations, were approximately $90 \%$ or greater than $90 \%$.

All the formulations showed greater than $62 \%$ drug entrapment. However, formulation F5 showed higher $(84.07 \%)$ drug entrapment efficiency than all other formulations. The low standard deviation values in the drug entrapment efficiency and drug content indicate that the values are uniform in all the batches of formulation.

The drug release from F1 to F3, where the drug:polymer ratio (1:1) showed slow and biphasic release until $12 \mathrm{~h}$ (fig. 2). It was observed that with increase in polymer concentration with respect to drug, there was no increase in percent drug release. This result indicates that higher concentration of polymer decreases the rate of drug release or it shows drug release retarding ability. All the drug release profiles showed biphasic release, with a fast release rate in the first two hours and a slow and gradual release rate over the next $12 \mathrm{~h}$. The quick release of the drug in the first two hours is probably from the unentrapped drug adsorbed on the polymer. The F5 formulation contains drug:polymer in the ratio of $1: 2$ with $2 \%$ PVA. The obtained nano suspension of F5 was further lyophilized to obtain dry nanoparticles, so that they could be used in formulation of nanoparticles loaded transdermal patch. Itraconazole nanoparticles loaded transdermal patches were prepared

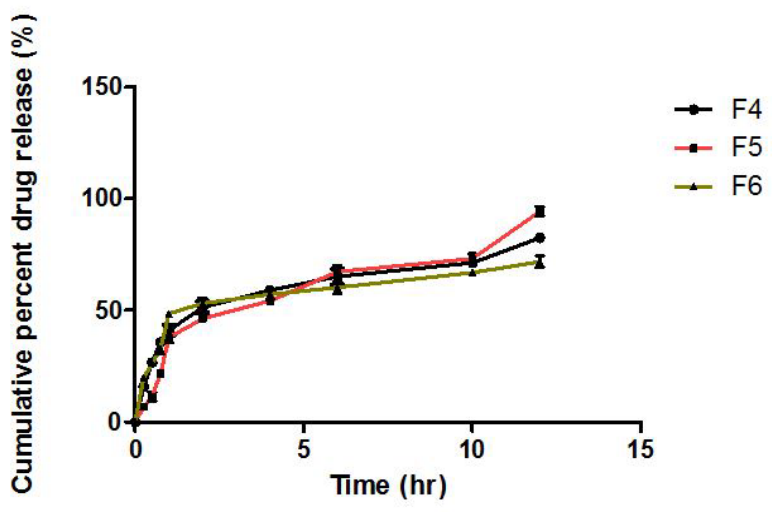

Fig. 2: Drug release profiles of prepared itraconazole nanoparticles (F4-F6)

TABLE 4: EVALUATION PARAMETER ITRACONAZOLE NANOPARTICLES LOADED TRANSDERMAL PATCH

\begin{tabular}{|c|c|c|c|c|c|}
\hline F. Code & $\begin{array}{c}\text { Thickness } \\
(\mathrm{mm})\end{array}$ & $\begin{array}{c}\text { Tensile strength } \\
\mathrm{kg} / \mathrm{cm}^{2}\end{array}$ & Folding endurance & $\begin{array}{c}\text { Moisture absorption/ } \\
\text { uptake (\%) }\end{array}$ & $\begin{array}{c}\text { Moisture } \\
\text { content (\%) }\end{array}$ \\
\hline FTP1 & $0.214 \pm 0.03$ & $0.932 \pm 0.02$ & $193 \pm 1.23$ & $9.17 \pm 0.08$ & $7.9 \pm 0.42$ \\
\hline FTP2 & $0.227 \pm 0.02$ & $1.023 \pm 0.06$ & $251 \pm 2.14$ & $11.22 \pm 0.98$ & $6.5 \pm 0.53$ \\
\hline FTP3 & $0.276 \pm 0.02$ & $1.825 \pm 0.01$ & $209 \pm 3.21$ & $14.21 \pm 0.24$ & $7.6 \pm 0.24$ \\
\hline FTP4 & $0.215 \pm 0.03$ & $1.432 \pm 0.07$ & $219 \pm 2.29$ & $14.25 \pm 0.08$ & $6.8 \pm 0.76$ \\
\hline FTP5 & $0.269 \pm 0.02$ & $1.654 \pm 0.06$ & $198 \pm 3.56$ & $15.34 \pm 0.45$ & $8.2 \pm 0.34$ \\
\hline FTP6 & $0.273 \pm 0.02$ & $1.952 \pm 0.12$ & $220 \pm 2.43$ & $16.75 \pm 0.63$ & $8.5 \pm 0.98$ \\
\hline
\end{tabular}

by using HPMC and PVP in different ratios (1:0.5, 1:1 and 1:2).

The results indicated that as the concentration of the polymer increased there was an increase in the thickness of the patch. The thickness values were in the range of $0.214 \pm 0.467$ to $0.276 \pm 0.914 \mathrm{~mm}$ (Table 4) which indicates that the patches were uniform.

The tensile strength of the patch prepared with HPMC and PVP were found to be in between $0.932-1.952 \mathrm{~kg} /$ $\mathrm{cm}^{2}$. It was observed that with the increase of PVP concentration and HPMC, the tensile strength of the patch gradually increased.

The folding endurance test is important to check the ability of the sample to withstand folding. This gives an indication of brittleness. The value of folding endurance was found between 193 and 251 folds which is considered satisfactory and reveals good film property.

The moisture uptake values in the patches were in the range of $9.17 \pm 0.08$ to $16.75 \pm 0.63 \%$. Low moisture uptake protects the material from microbial contamination and bulkiness.

The moisture content is in the range of $6.5 \pm 0.53$ to $8.5 \pm 0.98 \%$. The moisture content in the formulations was found to be increased by increase in the concentration of PVP and also with the increase the grade of HPMC. The lower moisture content in the formulations helps them to remain stable and become a completely dried and brittle film.

The drug content values are in the range of 96.73 to $98.84 \%$. The drug release profiles of itraconazole nanoparticles loaded transdermal patches are shown in fig. 3. The drug release was slow, biphasic and gradual, for all the formulations (FTP) from FTP1 to FTP6. However, the drug release was sustained for $12 \mathrm{~h}$ and maximum amount of drug was released from FTP2 batch. The release data were analyzed as per zero order, first order, Higuchi and Peppas equation models. 
The correlation coefficient ( $\mathrm{r}$ ) values in the analysis of release data as per various models are given Table 5 .

Analysis of the release data as per zero order and first order kinetic models indicated that the drug release from TDD patches formulated followed first order kinetics. All the formulations followed first order kinetics. This implies that the drug release is dependent on one of the concentration. The r-values were higher in first order model when compared to zero order models. The r-values were also more than 0.9238 in the Higuchi and Peppas equation models indicating that the drug release from the transdermal patches prepared also obeyed these two models. When the release date are analyzed as per Peppas equation, the release exponent ' $\mathrm{n}$ ' is an empirical parameter characterizing the release mechanism ${ }^{[36]}$. Mechanism of drug release may be determined based on the values of the diffusion exponent, if the value of $\mathrm{n}$ is 0.5 it indicates that the drug release mechanism is explained by a Fickian diffusion controlled release, whereas if $n$ equal to 1.0 , it indicates that the drug release mechanism approaches to zero order release. If $\mathrm{n}$ value is from 0.5 to 1 , it implies

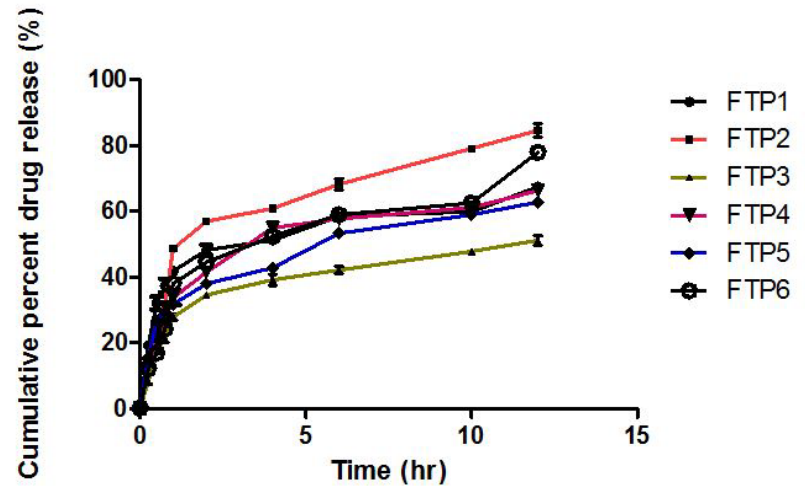

Fig. 3: Drug release profiles of nanoparticle loaded itraconazole transdermal patch that the release mechanism is non-Fickian diffusion or chain relaxation control release. The $n$ value of the formulations was in the range of 0.236 to 0.370 .

Hence, it was concluded that the prepared formulations followed Fickian diffusion. The drug release from all the batches followed by diffusion mechanism as Higuchi's fit shows high correlation coefficient values. Among all the formulations, from FTP1 to FTP6, FTP2 formulation gave good parameters and also maximum amount of drug was released within $12 \mathrm{~h}$. FTP2 formulation was selected for further comparative drug release and skin permeation studies. The in vitro release of itraconazole nanoparticles loaded transdermal patch (FTP2), from itraconazole ointment and from itraconazole gel is shown in fig. 4.

From this data it is obvious that the amount of drug released over a period of $6 \mathrm{~h}$, is higher from the gel and the ointment compared to FTP2. Prepared formulation showed a drug release profile which is slow, gradual, and sustained and gave extended release of the drug until $12 \mathrm{~h}$. The result indicated that the objective of controlled

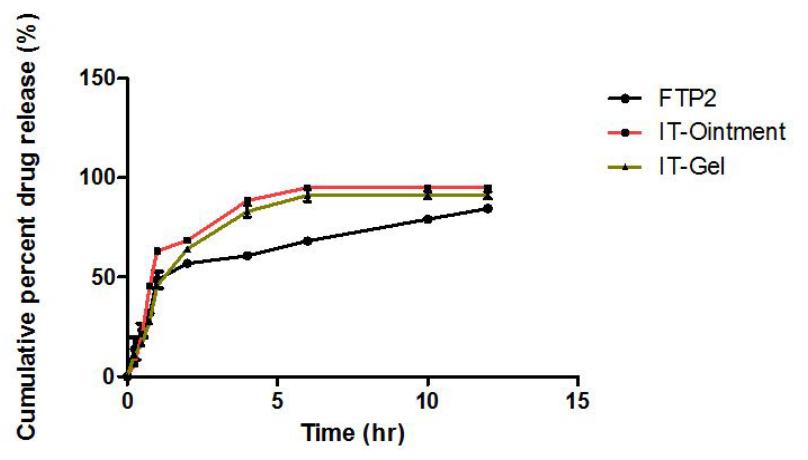

Fig. 4: Comparative permeation profiles (Ex vivo) of optimized formulation, itraconazole ointment and itraconazole gel

TABLE 5: CORRELATION COEFFICIENT (R) VALUES IN THE ANALYSIS OF RELEASE DATA AS PER ZERO ORDER, FIRST ORDER, HIGUCHI AND PEPPAS EQUATION MODELS

\begin{tabular}{lccccccc}
\hline Kinetic models & Parameters & FTP1 & FTP2 & FTP3 & FTP4 & FTP5 & FTP6 \\
\hline \multirow{4}{*}{ Zero order kinetics } & $\mathrm{K}_{\mathrm{o}}$ & 7.12 & 8.815 & 5.382 & 7.034 & 6.560 & 7.555 \\
& $\mathrm{~T}_{50}$ & 7.017 & 2.836 & 9.290 & 7.109 & 7.622 & 6.618 \\
& $\mathrm{~T}_{90}$ & 12.631 & 10.210 & 16.723 & 12.795 & 13.720 & 11.913 \\
& $\mathrm{r}$ & 0.7960 & 0.8613 & 0.8543 & 0.8599 & 0.8776 & 0.8886 \\
First order kinetics & $\mathrm{K}_{1}$ & 0.172 & 0.316 & 0.087 & 0.154 & 0.126 & 0.171 \\
& $\mathrm{~T}_{50}$ & 4.023 & 0.916 & 7.979 & 4.507 & 5.481 & 4.050 \\
& $\mathrm{~T}_{90}$ & 13.36 & 7.294 & 26.507 & 14.973 & 18.207 & 13.454 \\
Higuchi & $\mathrm{r}$ & 0.9718 & 0.9560 & 0.9965 & 0.9337 & 0.9237 & 0.9451 \\
Korsmeyer & $\mathrm{K}_{\mathrm{H}}$ & 23.101 & 27.737 & 17.032 & 22.227 & 20.751 & 23.475 \\
& $\mathrm{R}$ & 0.9138 & 0.9523 & 0.9524 & 0.9587 & 0.9643 & 0.9648 \\
Peppas & $\mathrm{K}_{\mathrm{kP}}$ & 37.678 & 37.873 & 23.969 & 30.760 & 30.315 & 29.937 \\
& $\mathrm{~N}$ & 0.2364 & 0.333 & 0.315 & 0.325 & 0.295 & 0.370 \\
\hline
\end{tabular}

K- Rate constant, $r$ - Correlation coefficient 
delivery of over a period of $12 \mathrm{~h}$ was achieved with the prepared formulation of FTP2.

In order to examine the drug permeation pattern, in vitro permeation study was carried out using Franz diffusion cell. Permeation profiles of FTP2, itraconazole ointment and itraconazole gel are shown in Table 6 and in fig. 5 .

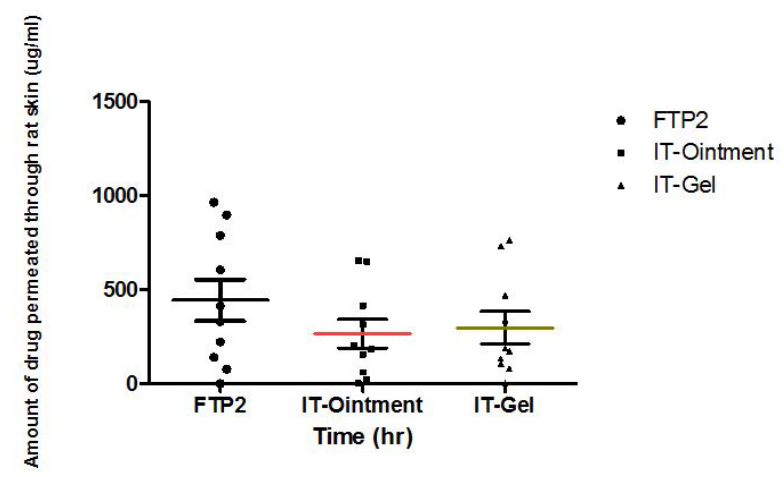

Fig. 5: Comparative Permeation profiles (Ex vivo) of optimized formulation, itraconazole ointment and itraconazole gel
Partition of the nanoparticles into stratum corneum is an important process as it drives the Nano particulate drug into the skin. Partitioning of high amount of nanoparticles will increase the flux while a faster partitioning will contribute to shorter lag time ${ }^{[37]}$. The results of skin permeation study through rat skin from formulation FTP2, ointment, gel and plain drug are depicted in fig. 5. The values of transdermal flux for FTP2, ointment, gel and plain drug were $63.24 \mu \mathrm{g} / \mathrm{cm}^{2} / \mathrm{h}, 39.15 \mu \mathrm{g} / \mathrm{cm}^{2} / \mathrm{h}, 40.01 \mu \mathrm{g} / \mathrm{cm}^{2} / \mathrm{h}$ and $23.95 \mu \mathrm{g} / \mathrm{cm}^{2} / \mathrm{h}$ respectively. The highest flux value was obtained for formulation FTP2. Almost 2.6 folds higher flux than that of pure itraconazole solution $\left(\mu \mathrm{g} / \mathrm{cm}^{2} / \mathrm{h}\right)$ was obtained (fig. 6).

Lag time required to reach a steady state was $4 \mathrm{~h}$ for plain drug and FTP2 reduced this lag time to $1 \mathrm{~h}$ and $2 \mathrm{~h}$. The permeability co-efficient and diffusion coefficient were calculated based on equations 1 and 2 . The permeability coefficient values were in the range of
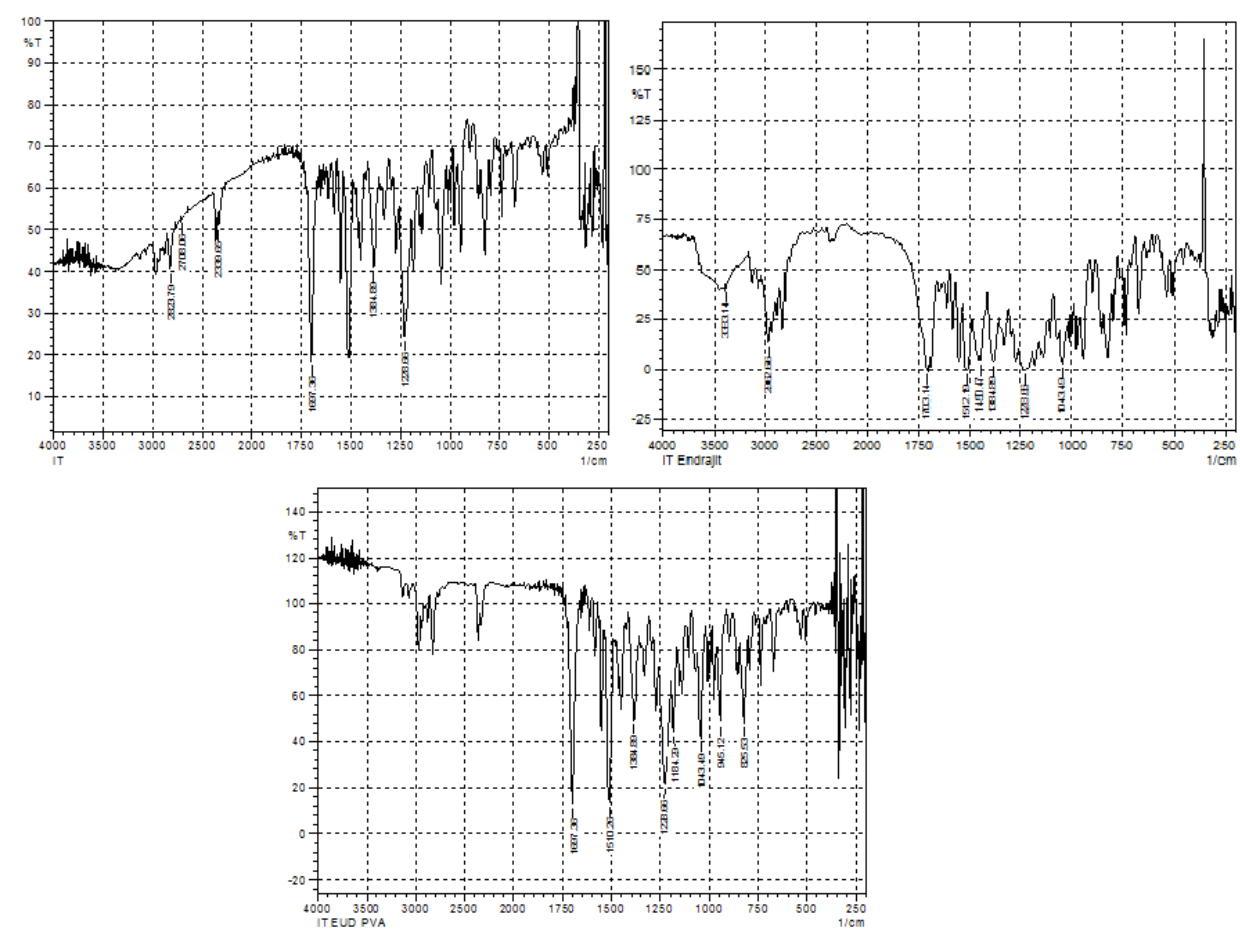

Fig. 6: Fourier transform infrared spectroscopy studies a) itraconazole b) Eudragit c) Optimized formulation

TABLE 6: PERMEATION KINETICS OF SELECTED FORMULATIONS ACROSS ARTIFICIALAND BIOLOGICAL MEMBRANE (RAT SKIN)

\begin{tabular}{|c|c|c|c|c|c|c|c|c|}
\hline F. code & Membrane & $\begin{array}{c}\text { Flux } \\
\left(\mu \mathrm{g} / \mathrm{cm}^{2} \mathrm{~h}\right)\end{array}$ & Lag time $h$ & 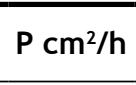 & $\begin{array}{c}\text { Diffusion coefficient } \\
\left(\mathrm{D} \times 10^{-4}\right)\end{array}$ & Best fit equation & $\mathbf{R}^{2}$ & $\begin{array}{c}\text { Enhancement } \\
\text { ratio }\end{array}$ \\
\hline FTP2 & cellophane & 42.34 & 2 & 0.07 & - & $Y=19.32 x+254.27$ & 0.9102 & - \\
\hline FTP2 & & 63.24 & 1 & 2.57 & 0.96 & $Y=63.009 x-19.075$ & 0.9991 & 2.63 \\
\hline Ointment & & 39.15 & 2 & 1.56 & 0.32 & $Y=39.144 x+2.995$ & 0.9733 & 1.63 \\
\hline Gel & Rat skin & 40.01 & 2 & 1.63 & 0.24 & $Y=40.064-43.281$ & 0.9917 & 1.68 \\
\hline $\begin{array}{l}\text { Pure } \\
\text { drug }\end{array}$ & & 23.95 & 4 & 0.95 & 0.24 & $Y=23.975 x+190.8$ & 0.9946 & .. \\
\hline
\end{tabular}



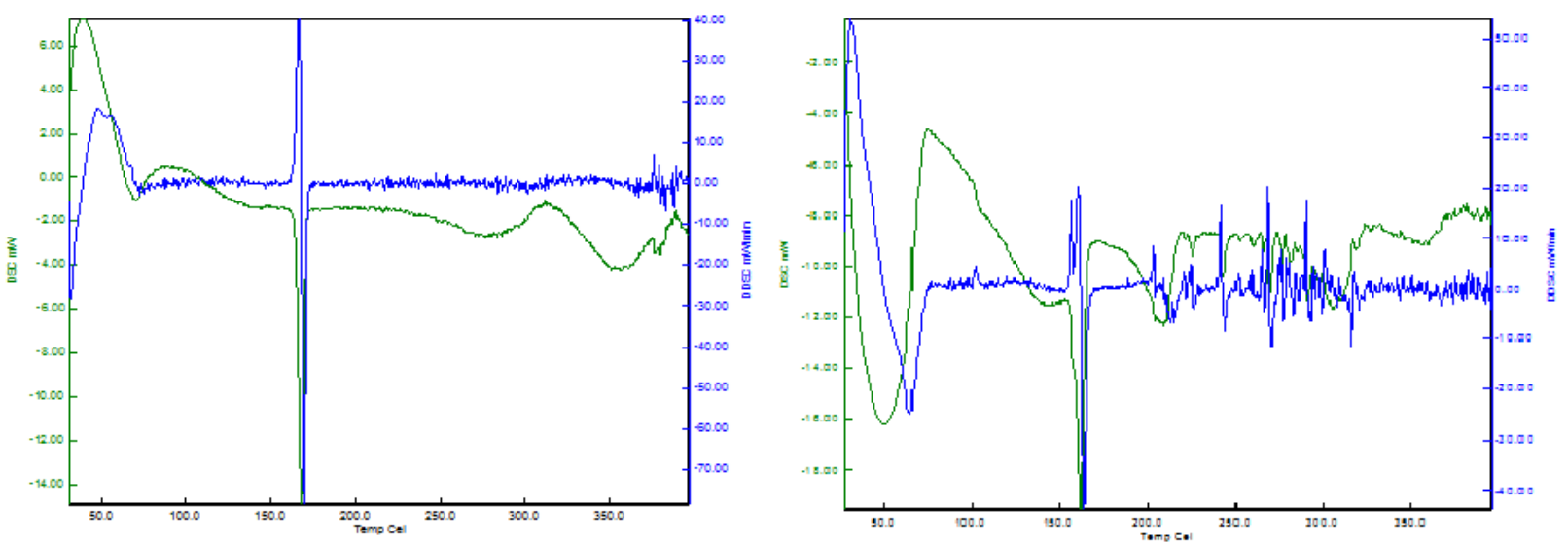

Fig. 7: Differential scanning calorimetry studies of pure drug and optimized formulation

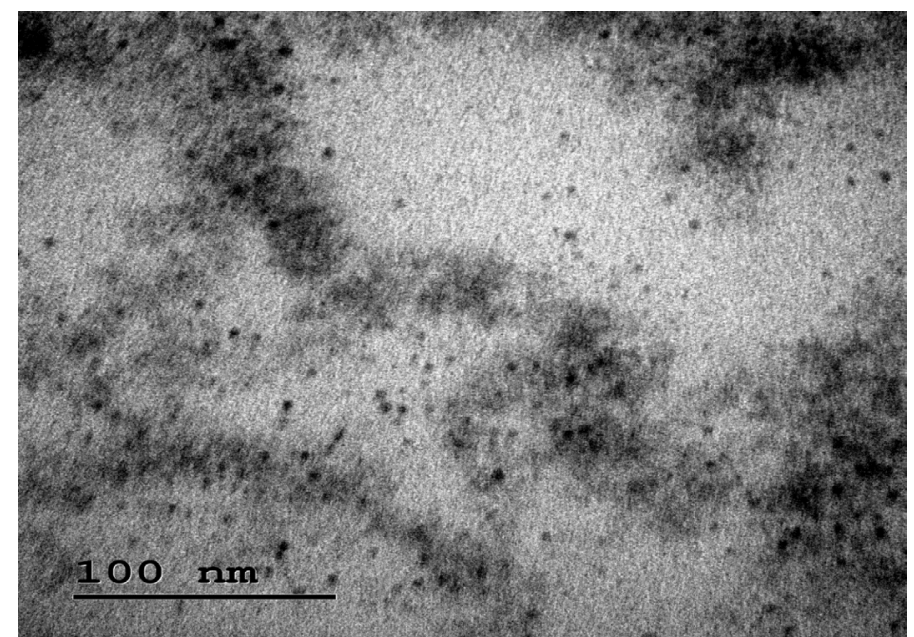

Fig. 8: Representative SEM image of transdermal patch FTP2 embedded with itraconazole loaded nanoparticles.

$0.95 \times 10^{-2}$ to $2.57 \times 10^{-2} \mathrm{~cm}^{2} / \mathrm{h}$, while diffusion coefficient values are in the range of $0.24 \times 10^{-4}$ to $0.96 \times 10^{-4} \mathrm{~cm}^{2} / \mathrm{h}$. The regression coefficient for the best fit equation for permeation plot values were in the range of 0.9733 to 0.9991 (fig. 7).

The enhancement ratio, calculated as transdermal flux from FTP2/transdermal flux from plain itraconazole solution, was 2.630. Highest enhancements in rate of permeation across the rat skin membrane per unit area per unit time. Results obtained from permeation studies across skin barrier have reported low flux values of itraconazole. This report suggested the possible reason of itraconazole topical ineffectiveness is its inadequate penetration through the stratum corneum. Hence, for optimal drug delivery, encapsulation of itraconazole in polymeric Nano particulate system and incorporating these nanoparticles in a transdermal patch would be a good approach. Moreover, there was no significant variation for all the tested preparations in vitro. This indicates the effectiveness of applied polymeric films, over other tested topical preparations.
SEM image (fig. 8) revealed that in the nanoparticles embedded transdermal patch, there is no effect in size or shape of nanoparticles, indicating the acceptability of this formulation.

The results obtained in the present work showed that nanoparticle loaded transdermal patch prepared by using Eudragit, HPMC and PVP, as a suitable carrier system for incorporation of itraconazole and satisfies the best attributes for transdermal applications with nano range particle size, suitable release profiles. The prepared patches were stable and safe for transdermal delivery. The developed system could able to release the drug in sustained pattern and thereby it might reduce frequency of administration and improves patient compliance.

\section{Conflict of interests:}

The authors declared no conflict of interest.

\section{Acknowledgement:}

Authors are thankful to Drug Testing Laboratory, Bangalore for sample analysis and also to Shri Dr Lavu Rathaiah, Chairman, Vignan group of institutions for 
providing the necessary facilities for carrying out this research work.

\section{REFERENCES}

1. Prausnitz MR, Langer R. Transdermal drug delivery. Nat Biotechnol 2008;26(11):1261-8.

2. Tanner T, Marks R. Delivering drugs by the transdermal route: review and comment. Skin Res Technol 2008;14(3):249-60.

3. Durand C, Alhammad A, Willett KC. Practical considerations for optimal transdermal drug delivery. Am J Health Syst Pharm 2012;69(2):116-24.

4. Samad A, Ullah Z, Alam MI, Wais M, Shams MS. Transdermal drug delivery system: patent reviews. Recent Pat Drug Deliv Formul 2009;3(2):143-52.

5. Gupta H, Babu RJ. Transdermal delivery: product and patent update. Recent Pat Drug Deliv Formul 2013;7(3):184-205.

6. Agrawal SS, Munjal P. Permeation studies of atenolol and metoprolol tartrate from three different polymer matrices for transdermal delivery. Indi J Pharm Sci 2007;69(4):535.

7. Darwhekar G, Jain DK, Patidar VK. Formulation and evaluation of transdermal drug delivery system of clopidogrel bisulfate. Asian J Pharm Life Sci 2011;2231:4423.

8. Cleary GW, Beskar E. Transdermal and transdermal like delivery system opportunities. Business Briefing: Pharm Tech 2004:1-4.

9. Barry BW, BW B. Dermatological formulations: percutaneous absorption. J Pharm Sci 1983;73:27-233.

10. Smith EW, Maibach HI. Percutaceous penetration enhancement. Boca Raton, Taylor \& Francis Group 2006:3-15.

11. Wagner H, Kostka KH, Adelhardt W, Schaefer UF. Effects of various vehicles on the penetration of flufenamic acid into human skin. Eur J Pharm Biopharm 2004;58(1):121-9.

12. Kulkarni RV, Mutalik S, Hiremath D. Effect of plasticizers on the permeability and mechanical properties of Eudragit films fortransdermal application. Ind J Pharm Sci 2002;64(1):28-31.

13. Barry BW. Novel mechanisms and devices to enable successful transdermal drug delivery. Eur J Pharm Sci 2001;14(2):101-14.

14. Mukherjee B, Kanupriya MS, Das S, Patra B. Sorbitan monolaurate 20 as a potential skin permeation enhancer in transdermal patches. J Appl Res 2005;1:96-108.

15. Boddeda B, Mohan K, Jhansi G, Harani A, Vijaya Ratna J, Srinivasa Rao Y. Ibuprofen-loaded acrylate polymeric nanosuspensions: characterization, in vitro and in vivo antiinflammatory activity. Pharm Nanotechnol 2015;3(2):101-10.

16. Shen LN, Zhang YT, Wang Q, Xu L, Feng NP. Enhanced in vitro and in vivo skin deposition of apigenin delivered using ethosomes. Int J Pharm 2014;460(1-2):280-8.

17. Verma P, Pathak K. Nanosized ethanolic vesicles loaded with econazole nitrate for the treatment of deep fungal infections through topical gel formulation. Nanomedicine 2012;8(4):48996.

18. Tekade AR, Gattani SG. Investigation on Physical-Mechanical properties of natural polymer films. Int $\mathrm{J}$ Pharm Tech Res 2010;2(1):106-12.

19. Paolino D, Celia C, Trapasso E, Cilurzo F, Fresta M. Paclitaxelloaded ethosomes ${ }^{\circledR}$ : potential treatment of squamous cell carcinoma, a malignant transformation of actinic keratoses. Eur J Pharm Biopharm 2012;81(1):102-12.

20. Lecomte F, Siepmann J, Walther M, MacRae RJ, Bodmeier R. Polymer blends used for the aqueous coating of solid dosage forms: importance of the type of plasticizer. J Control Release 2004;99(1):1-3.

21. Zhang X, Wang Y, Wang J, Wang Y, Li S. Effect of pore former on the properties of casted film prepared from blends of Eudragit ${ }^{\circledR}$ NE 30 D and Eudragit ${ }^{\circledR}$ L 30 D-55. Chem Pharm Bull 2007;55(8):1261-3.

22. Basu B, Garala K, Tyagi M, Prabhushankar GL, Babu PR. Formulation and in vitro evaluation of periodontal films containing metronidazole. Res J Pharm Dosage Forms Technol 2009;1(3):240-3.

23. Boddeda B, Suhasini MS, Niranja P, Ramadevi M, Anusha N. Design, evaluation and optimization of fluconazole transdermal patch by 22 factorial method. Der Pharmacia Lettre 2016;8(5):280-7.

24. Garala KC, Shinde AJ, Shah PH. Formulation and in vitro characterization of monolithic matrix transdermal systems using HPMC/Eudragit S 100 polymer blends. Int J Pharm Pharm Sci 2009;1(1):108-20.

25. Ubaidulla U, Reddy MV, Ruckmani K, Ahmad FJ, Khar RK. Transdermal therapeutic system of carvedilol: effect of hydrophilic and hydrophobic matrix on in vitro and in vivo characteristics. Aaps Pharm Sci Tech 2007;8(1):E13-20.

26. Awen BZ, Katakam P, Rao CB, Mohammed SA, Alokbe TO. Design and in vitro evaluation of controlled release cephalexin subgingival films using natural biodegradable polymer. Recent Res Sci Technol 2010;2(4):6-11.

27. Nakano M, Kuchiki A, Arita T. The effect of charges on permeabilities of drugs through collagen membranes. Chem Pharm Bull 1976;24(10):2345-9.

28. Aqil M,Ali A. Monolithic matrix type transdermal drug delivery systems of pinacidil monohydrate: in vitro characterisation. Eur J Pharm Biopharm 2002;54(2):161-4.

29. Costa P, Lobo JM. Modeling and comparison of dissolution profiles. Eur J Pharm Sci 2001;13(2):123-33.

30. Montanari J, Perez AP, Di Salvo F, Diz V, Barnadas R, Dicelio L, et al. Photodynamic ultradeformable liposomes: design and characterization. Int J Pharm 2007;330(1-2):183-94.

31. Panigrahi L, Pattnaik S, Ghosal SK. The effect of $\mathrm{pH}$ and organic ester penetration enhancers on skin permeation kinetics of terbutaline sulfate from pseudolatex-type transdermal delivery systems through mouse and human cadaver skins. AAPS Pharm Sci Tech 2005;6(2):E167-73.

32. Tiwari RK, Chauhan NS, Yogesh HS. Ethosomes: A potential carries for transdermal drug delivery. Int J Drug Dev Res 2010;2(2):448-52.

33. Martin A, Swarbrick J, Cammarata A. Physical pharmacy: physical chemical principles in the pharmaceutical sciences. BI Waverly Pvt Ltd; 2001:303.

34. Suresh S, Joshi HP. Preparation and evaluation of mouth dissolving tablets of salbutamol sulphate. Ind J Pharm Sci 2007;69(3):467.

35. Sternling CA, Scriven LE. Interfacial turbulence: hydrodynamic instability and the Marangoni effect. AIChE J 1959;5(4):514-23.

36. Korsmeyer RW, Gurny R, Doelker E, Buri P, Peppas NA. Mechanisms of solute release from porous hydrophilic polymers. Int J Pharm 1983;15(1):25-35.

37. Honeywell-Nguyen PL, Bouwstra JA. The in vitro transport of pergolide from surfactant-based elastic vesicles through human skin: a suggested mechanism of action. J Control Release 2003;86(1):145-56. 